\title{
Introduction to Born Digitals Minitrack
}

\author{
Minna Rollins \\ University of West Georgia \\ mrollins@westga.edu
}

Arto Ojala

University of Vaasa

arto.ojala@uwasa.fi

\author{
Mika Gabrielsson \\ University of Eastern Finland \\ mika.gabrielsson@uef.fi \\ Sara Fraccastoro \\ University of Eastern Finland \\ sara.fraccastoro@uef.fi
}

Our minitrack, Born Digitals, explores the impact and role of digitalization in global groups and organizations. The success of the firm's entrepreneurial activities, international business operations, management, and marketing depends on practical learning and knowledge coordination. Our minitrack covers aspects related to several fields such as entrepreneurship, marketing, management, international business, digitalization, knowledge-intensive firms like born digitals, and the role of culture within these contexts.

We accepted two papers to our minitrack. The first paper, authored by Baber and Yao, focuses on the value co-creation mechanism of the value constellation of a digital services platform. Authors investigate, Kuaishou, a Chinese born-digital platform business. Kuaishou is among the largest shortform video platforms globally, connecting makers, shoppers, performers, advertisers, and others. Baber and Yao discuss the business model of Kuaishou as well as apply the value constellation model.

The second paper in this minitrack by Ye, Kang, and Scott-Kennel examines the path of digital firms' international expansion. The authors examined 25 firms from the top 100 digital multinational enterprises and identified three digital firms' internationalization patterns. Based on their findings, Ye, Kang, and Scott-Kennel suggest that the internationalization of born digitals challenges traditional internationalization theory.

We want to thank all authors and reviewers. 
Page 5137 